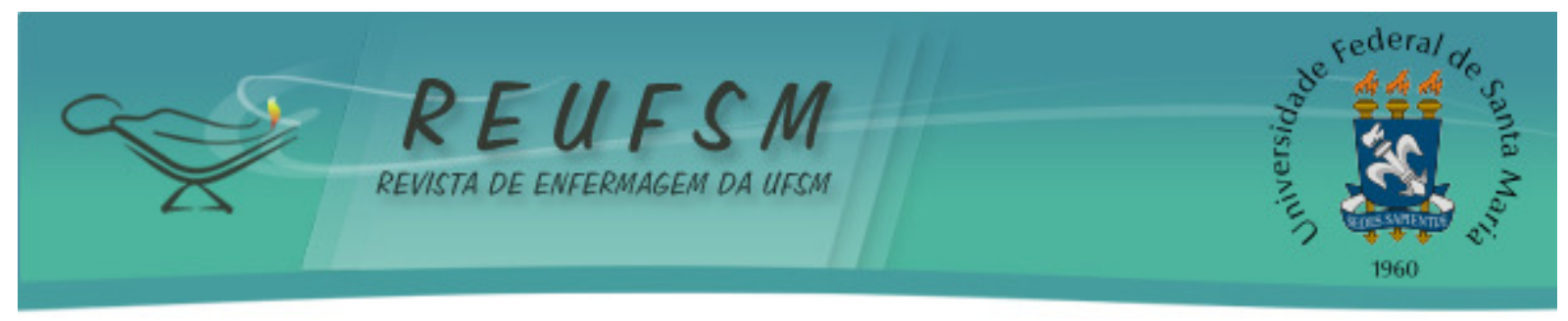

ARTIGO ORIGINAL

\title{
O SIGNIFICADO DO CUIDADO PERIOPERATÓRIO PARA O IDOSO
}

THE MEANING OF PREOPERATIVE CARE FOR THE ELDERLY

EL SIGNIFICADO DE LA ATENCIÓN PERIOPERATORIO PARA EL ANCIANO

\author{
Simone Domingues Garcia ${ }^{1}$ \\ Mara Lúcia Garanhani ${ }^{2}$ \\ Cibele Cristina Tramontini ${ }^{3}$ \\ Marli Terezinha Oliveira Vannuchi ${ }^{4}$
}

Doi: $10.5902 / 2179769210257$

RESUMO: Objetivo: identificar o significado do cuidado perioperatório para pacientes idosos. Método: pesquisa qualitativa descritiva realizada com nove pacientes idosos de ambos os sexos em um hospital universitário do norte do Paraná. Os dados foram coletados por entrevistas semiestruturadas pré-agendadas com os participantes. Resultados: a análise possibilitou a construção de três categorias: o idoso e a hospitalização cirúrgica, o idoso e o autocuidado e o significado de cuidar para o idoso. Conclusão: observou-se a singularidade dos significados de cuidado expressos e que estes influenciam no tratamento. A comunicação adequada pela equipe de saúde mostrou-se como importante estratégia para proporcionar maior conforto. Considerando a enfermagem como agente do cuidado, desenvolver uma equipe preparada para atender às alterações provenientes da idade e do procedimento cirúrgico tornou-se fundamental para qualificar o atendimento ao idoso. A atenção e apoio emocional revelaram-se significativas no momento perioperatório, caracterizando como imprescindível a humanização no processo do cuidar.

Descritores: Cirurgia geral; Idoso; Assistência perioperatória; Cuidados de enfermagem.

ABSTRACT: Aim: to identify the significance of perioperative care for elderly patients. Method: qualitative anddescriptive research held with nine elderly patients of both genres in a university hospital in northern Paraná. Data were collected through semistructured interviews pre-arranged with the participants. Results: the analysis enabled the construction of three categories: the elderly surgical and hospitalization, the elderly and the meaning of self-care and care for the elderly. Conclusion: it was observed the uniqueness of meanings of care expressedand their influence in the treatment. Adequate communication by healthcare was an important strategy to provide greater comfort. Considering nursing as care agent, develop a team prepared to meet the changes coming of age and surgical procedure has become critical to improve care for the elderly. The attention and emotional support were significant when perioperative characterized as essential to humanizing the care process.

Descriptors: General surgery; Aged; Perioperative care; Nursing care.

\footnotetext{
${ }^{1}$ Enfermeira. Mestre em Enfermagem pela Universidade Estadual de Londrina, UEL. Universidade Estadual de Londrina, UEL, PR, Brasil. E-mail: sidomingues@yahoo.com.br

${ }^{2}$ Enfermeira. Doutora em Enfermagem pela Escola de Enfermagem de Ribeirão Preto, USP. Docente do Departamento de Enfermagem da Universidade Estadual de Londrina, UEL, PR, Brasil. E-mail: maragara@hotmail.com

${ }^{3}$ Enfermeira. Doutoranda em Enfermagem pela Escola de Enfermagem de Ribeirão Preto, USP. Docente do Departamento de Enfermagem da Universidade Estadual de Londrina, UEL, PR, Brasil. E-mail: beletramontini@hotmail.com

${ }^{4}$ Enfermeira. Doutora em Saúde Pública pela Universidade de São Paulo, USP. Docente do Departamento de Enfermagem da Universidade Estadual de Londrina, UEL, PR, Brasil. E-mail: vannuchi@sercomtel.com.br
} 


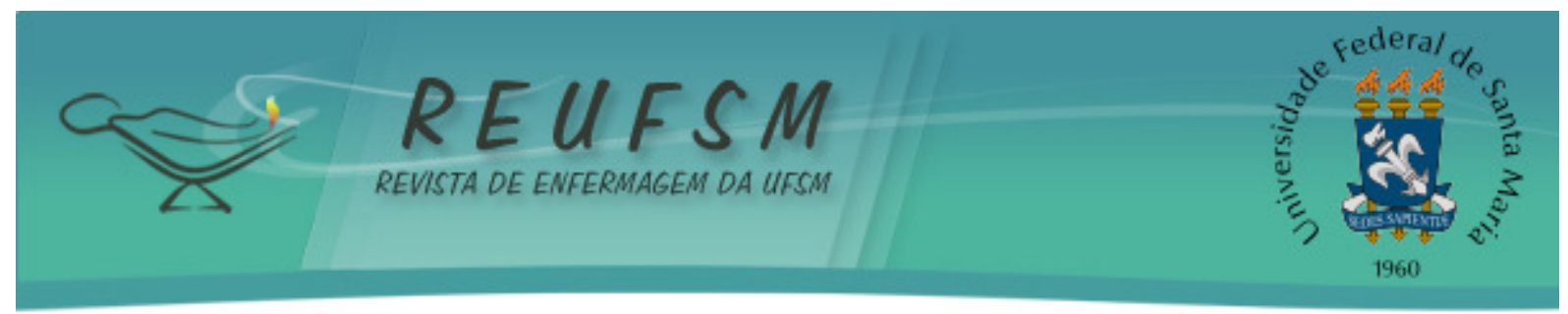

RESUMEN: Objetivo: identificar el significado del cuidado perioperatorio en pacientes ancianos. Método: investigación descriptiva cualitativa realizada con nueve ancianos en hospital universitario del Paraná. Los datos fueron recolectados a través de entrevistas semi-estructuradas previamente concertadas con los participantes. Resultados: fueron identificadas tres categorías: Los ancianos y la hospitalización quirúrgica, el auto-cuidado y el significado del cuidar para los ancianos. Conclusión: fue observado la singularidad de significados del cuidado y que estos influyen en el tratamiento. La comunicación adecuada del equipo de salud se mostró una importante estrategia para proporcionar mayor comodidad. Teniendo en cuenta la enfermería como agente de atención, desarrollar un equipo preparado para cumplir con los cambios que vienen de la edad y el procedimiento quirúrgico se ha convertido en fundamental para mejorar la atención a los ancianos. La atención y el apoyo emocional fueron significativos en el momento perioperatorio, caracterizando esencial para la humanización del proceso de atención.

Descriptores: Cirugía general; Anciano; Atención perioperativa; Atención de enfermería.

\section{INTRODUÇÃO}

O crescimento da população idosa reflete em mudanças significativas na área da saúde, principalmente, em decorrência do aumento do número de doenças crônicas degenerativas associadas aos agravos da senescência. Esse fator influencia o número de hospitalizações e recursos despendidos aumentando-os. Mais recentemente, observou-se também a elevação de procedimentos cirúrgicos nesta faixa etária, pois, estes apresentam-se como opções de tratamento seguro, frente aos avanços tecnológicos envolvidos no diagnóstico, cirurgia e anestesia. ${ }^{1}$

A assistência ao idoso em situação cirúrgica difere dos outros grupos etários devido às mudanças decorrentes do processo de envelhecimento e a presença de doenças associadas, que podem ser significativas para o equilíbrio funcional aumentando a vulnerabilidade para alterações pós-operatórias. ${ }^{1}$

Com isso, o cuidado prestado pela equipe de saúde no momento cirúrgico torna-se imprescindível, bem como compreender o contexto das percepções dos profissionais envolvidos com este cuidado. Autores colocam a importância de o cuidado ser visto como uma atitude de desvelo, preocupação e inquietação pela pessoa que está sendo cuidada. Reforçam também que a complexidade no cuidado caracteriza a necessidade de uma atuação multiprofissional, buscando a preservação da autonomia e da individualidade do ser humano. ${ }^{2}$

Ressalta-se que os procedimentos de cuidado realizados durante o período de internação, considerados de rotina para o profissional, apresentam diferentes significados para o paciente idoso. Para eles, as crenças, valores, normas e ritos de cuidados têm uma poderosa influência na sobrevivência humana, crescimento, estado de doença, saúde e bem estar. ${ }^{3}$

No Brasil, o avanço das técnicas cirúrgicas e a popularização da cirurgia promoveram a expansão dos cuidados de enfermagem para essa clientela. Contudo, apesar da importância da temática e do interesse de vários países nesse assunto, a atuação da enfermagem nessa área ainda está voltada para diretrizes médicas, haja vista o pouco número de publicações realizadas em nosso país sobre o tema. ${ }^{4}$

Porém, sua importância é incontestável visto que a equipe de enfermagem que trabalha em Centro Cirúrgico (CC) presta cuidados aos pacientes cirúrgicos envolvendo aspectos fisiológicos, emocionais, sociais, entre outros. O cuidado inicia-se antes da cirurgia em si, no momento em que o paciente toma ciência da necessidade do procedimento até a admissão do paciente no bloco cirúrgico e a organização da alta dessa 


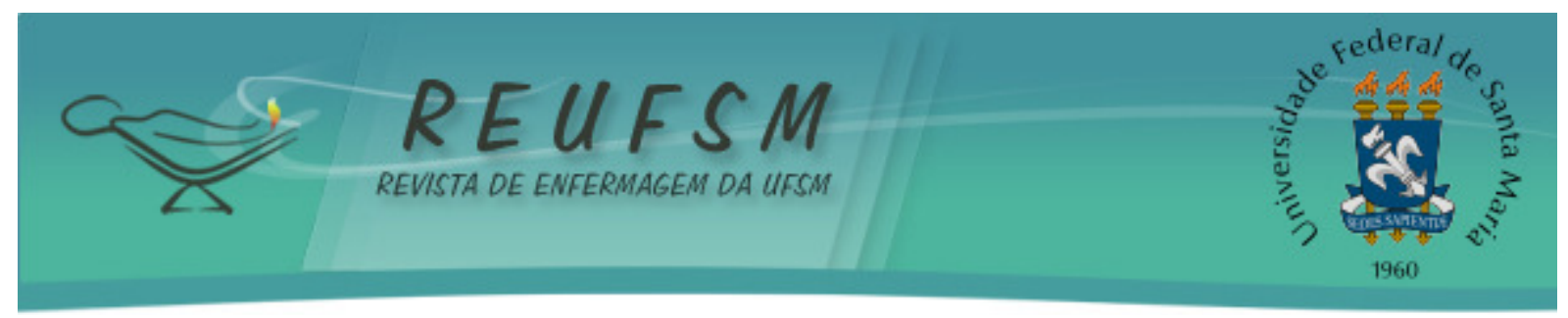

unidade. A equipe de enfermagem atua prestando assistência específica, buscando diminuir ansiedades, esclarecendo dúvidas e amenizando medos. ${ }^{5}$

A questão norteadora do estudo pautou-se em qual o significado do cuidado para os idosos, e como esses sentiram-se cuidados durante o período perioperatório. Acredita-se que o desvelamento destas percepções poderá contribuir para o aperfeiçoamento da qualidade do cuidado prestado pela equipe de saúde, diminuindo assim, possíveis lacunas vivenciadas na assistência integral ao idoso.

A partir dessas considerações, o objetivo desta pesquisa foi identificar o significado do cuidado para pacientes idosos durante o perioperatório.

\section{MÉTODO}

Trata-se de um estudo descritivo de abordagem qualitativa, na modalidade da estrutura do fenômeno situado. ${ }^{6}$ Realizou-se nas unidades feminina e masculina de um hospital universitário público do norte do Paraná, considerado centro de referência regional para o Sistema Único de Saúde (SUS) com assistência em praticamente todas as especialidades médicas, possuindo 316 leitos atendidos 100\% pelo SUS. O Centro Cirúrgico da instituição possui uma média de 600 cirurgias/mês, contemplando pacientes em todas as faixas etárias. O período do estudo correspondeu de abril a maio de 2009.

Foram feitas visitas prévias as unidades de internação para verificação do agendamento cirúrgico, e a seleção de qual paciente seria convidado para a pesquisa era feita em consenso com a supervisão de enfermagem da unidade. Os pacientes eram abordados conforme a disponibilidade, sendo solicitado um momento de diálogo pelo entrevistador para que pudesse explicar os objetivos do estudo. Caso aceitasse participar era disponibilizado o termo de consentimento livre e esclarecido contendo todas as informações importantes da pesquisa. Inicialmente, era realizada uma visita para um primeiro contato com o paciente antes da entrevista, e após era agendado um local e horário de sua preferência para a realização.

Considerou-se idoso aquele com 60 anos ou mais de acordo com Política Nacional do Idoso. Como instrumento de coleta de dados utilizou-se entrevistas semi-estruturadas realizadas com nove pacientes idosos de ambos os sexos. O número de entrevistados foi estabelecido de acordo com a justificativa metodológica de saturação dos dados obtidos durante as entrevistas, sem conter um número pré-estabelecido. Os critérios de inclusão foram: idade; orientação espacial satisfatória pelo paciente conforme avaliação neurológica contida na prescrição de enfermagem; estar no período pós-operatório; estar em condições físicas e psíquicas compatíveis para o diálogo.

Foram utilizadas questões que abrangessem o cuidado recebido como um todo e que fossem de fácil compreensão para o paciente. As questões foram: Como o senhor (a) foi orientado (a) para a cirurgia?; Teve alguma necessidade que o(a) senhor(a) achou que não foi atendida?; Quais cuidados foram feitos? Como o(a) senhor(a) se cuida?; E o que é cuidado para o(a) senhor(a).

As entrevistas foram gravadas e, após a sua realização foram transcritas na íntegra e, na sequência, foram retirados os vícios de linguagem, possibilitando uma leitura mais contínua das experiências dos sujeitos envolvidos. Após a utilização dos dados as falas foram apagadas do gravador.

A identificação dos entrevistados foi preservada nas falas, sendo numerada pelo autor de acordo com o diálogo e as unidades de significado, como exemplo, D1 para diálogo 1 e US1 para unidade de significado 1, sendo numerados de acordo com a ordem em que foram entrevistados.

Para a análise dos dados, foi utilizada a sequência de análise de discurso na modalidade da estrutura do fenômeno situado, composta por dois momentos. 0 primeiro 


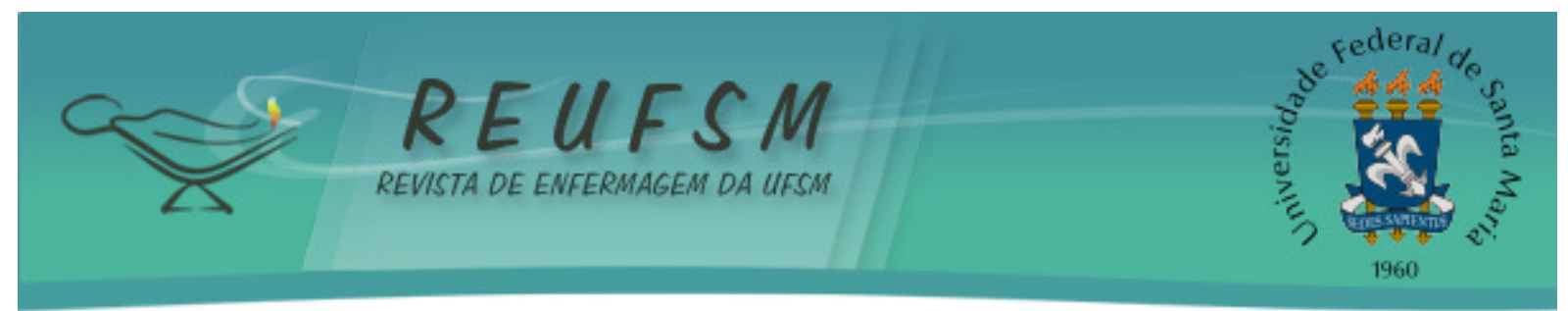

constitui-se pela análise ideográfica que é dividida em quatro etapas: leitura da descrição do início ao fim sem buscar qualquer interpretação ou identificação de atributo ou elemento; apreensão das unidades de significado; interpretação das mesmas e a síntese das unidades. O segundo momento, denominado de análise nomotética, busca o alcance da estrutura geral psicológica, proporcionando um movimento de convergências e divergências que se mostrarão nos casos individuais. ${ }^{7}$

As questões formuladas foram testadas em duas entrevistas pilotos para verificar a facilidade de compreensão das normas e se estavam oportunizando respostas que descrevessem o fenômeno estudado.

Este trabalho faz parte do Projeto de Pesquisa intitulado "O cuidado perioperatório para o paciente, familiares, equipe de saúde e alunos", cadastrado na Próreitoria de pesquisa e pós-graduação da Universidade Estadual de Londrina $N^{\circ} 05429$ e aprovado no Comitê de Ética e pesquisa da instituição na data de 09/09/2008 com outras pesquisas sendo realizadas até os dias atuais. Possui o número de cadastro no CAAE $N^{\circ}$ 0115.0.268.000-08. A pesquisa foi conduzida seguindo todos os padrões éticos exigidos.

\section{RESULTADOS E DISCUSSÃO}

0 grupo de estudo foi constituído por quatro homens entre 60 e 71 anos, e cinco mulheres entre 60 e 75 anos. Os homens foram submetidos a diferentes tipos de cirurgia, sendo: cirurgia do aparelho digestivo, cirurgia vascular, cirurgia abdominal e cirurgia do aparelho urinário. As cirurgias das mulheres foram: cirurgia abdominal, cirurgia ortopédica, implante de marcapasso, retirada de lipoma e cirurgia vascular. Quanto ao grau de escolaridade, três eram analfabetos e os outros seis possuíam primeiro grau incompleto.

A análise das entrevistas possibilitou a construção de três categorias: 0 idoso e a hospitalização cirúrgica, o idoso e o autocuidado e o significado de cuidar para o idoso.

\section{O idoso e a hospitalização cirúrgica}

Nessa categoria as orientações relacionadas ao cuidado enfatizaram temas importantes como: a compreensão do paciente cuidado sobre as circunstâncias que envolveram o seu agravo de saúde; o período de jejum; referência aos profissionais da equipe que cuidaram dele; percepções positivas do atendimento recebido; conflitos na equipe de saúde; falta de informação; a ausência dos familiares e o impacto da espiritualidade.

A fala a seguir exemplifica a compreensão do paciente cuidado:

A orientação que me deram era que eu não deveria usar mais tapetes, eu vou avisar minha filha para não usar mais, sabe? (D5US11)

0 paciente refere que o tapete, objeto citado, foi o desencadeador de sua queda, e a retirada dele diminuiria os riscos do ambiente. Este entendimento demonstra que a orientação foi adequada e atingiu o objetivo de prevenção de outros acidentes.

As orientações devem sempre respeitar o nível de instrução de cada paciente e serem adequadas a cada fase do tratamento. Para que o profissional realize adequadamente a educação em saúde e o paciente compreenda é importante que a comunicação seja eficaz, algo de grande importância no meio hospitalar, já que em muitos casos os cuidados se estenderão ao domicílio. ${ }^{3}$

Em relação ao período de jejum foram citadas as falas: 


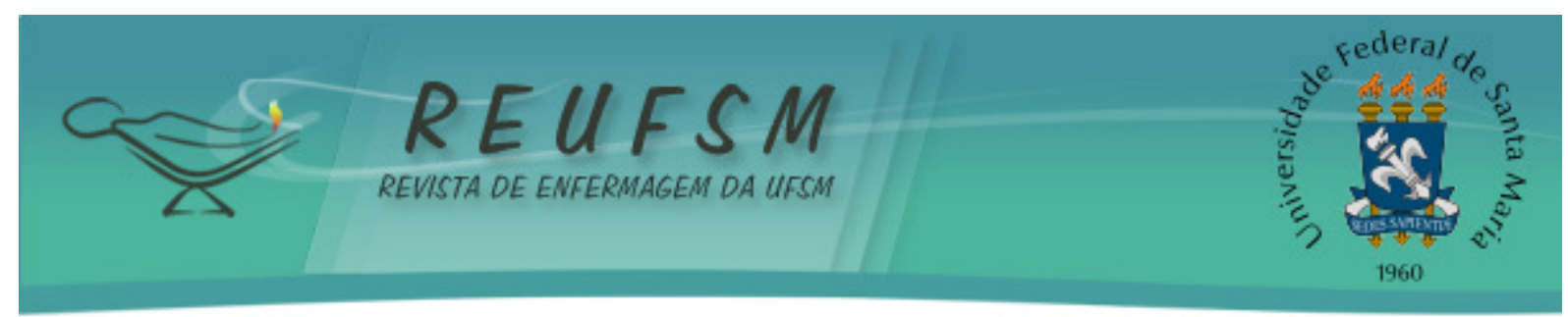

Foi orientado para eu não comer, para ficar dois dias de jejum e depois eu só poderia um suco só de noite, porque aí de manhã já dava para comer uma coisinha. (D1US1)

Para ter cuidado, porque não pode tomar só leite, ficar dois dias de jejum antes, depois de tomar só leite e esperaR senão complica mais. (D1US5)

Os discursos demonstram que o problema que caracterizava a necessidade de procedimento cirúrgico alterava drasticamente a alimentação do paciente, exigindo cuidado para não atrapalhar sua recuperação. Foi perceptível encontrar ênfase nos relatos dos pacientes em relação ao jejum, citando dias e valorizando esta informação.

A necessidade deste cuidado para realização dos procedimentos cirúrgicos é muito relevante. É de conhecimento da equipe e orientado aos pacientes que o não cumprimento do período adequado do jejum representa, além de um risco, uma possibilidade de cancelamento cirúrgico. Esta possibilidade de cancelamento assusta os pacientes, pois além de aumentar os dias de internamento, a sua cirurgia precisará ser remarcada. Nesta situação ele corre o risco de até mesmo perder a cirurgia, tendo a necessidade de entrar novamente na fila de agendamento do SUS.

A alimentação do paciente cirúrgico tem suas particularidades que devem ser explicadas com clareza para que a frustração da falta do alimento (período de jejum pré e em alguns casos pós-operatório) seja sanada pela informação adequada. Em determinadas situações o alimento é utilizado como meio de sanar medos e angústias, podendo trazer danos no decorrer do tratamento, caso a dieta adequada não seja seguida. Enfatiza-se, ainda, que a alimentação do paciente idoso apresenta algumas peculiaridades fisiológicas e culturais que precisam ser consideradas e valorizadas pelos profissionais da saúde.

Em relação à referência dos profissionais foram citados: médico, fisioterapeuta, enfermeiro e o cuidador, no caso, a filha de uma paciente entrevistada. Houve relato de envolvimento emocional com a equipe no geral, o que caracteriza o serviço de forma positiva:

Olha a fisioterapia fez o trabalho direito. (D5US4)

Os médicos todos bons, as enfermeiras todas boas. (D6US7)

Os pacientes demonstraram percepções positivas com o atendimento recebido:

Tem cuidado bem, tem atendido eu muito bem. (D2US13)

Eu estou satisfeito com o atendimento, bem atendido. (D4US8)

As opiniões demonstradas com o atendimento recebido fortalecem características satisfatórias perante a equipe, evidenciando que idosos, após o procedimento cirúrgico, recordam-se de aspectos positivos em detrimento de situações que apresentaram desconforto.

A expectativa do indivíduo em relação à hospitalização, ao tratamento e à qualidade do cuidado é um fator que pode repercutir na sua recuperação. O paciente cirúrgico exige uma assistência de enfermagem fundamentada nas necessidades provenientes de fatores associados, como o procedimento anestésico cirúrgico ou pelas ocorrências oriundas da dinâmica do preparo do ambiente, do indivíduo, respeitando seus valores e promovendo interações para melhorar sua condição de enfrentamento da cirurgia. ${ }^{8}$ 


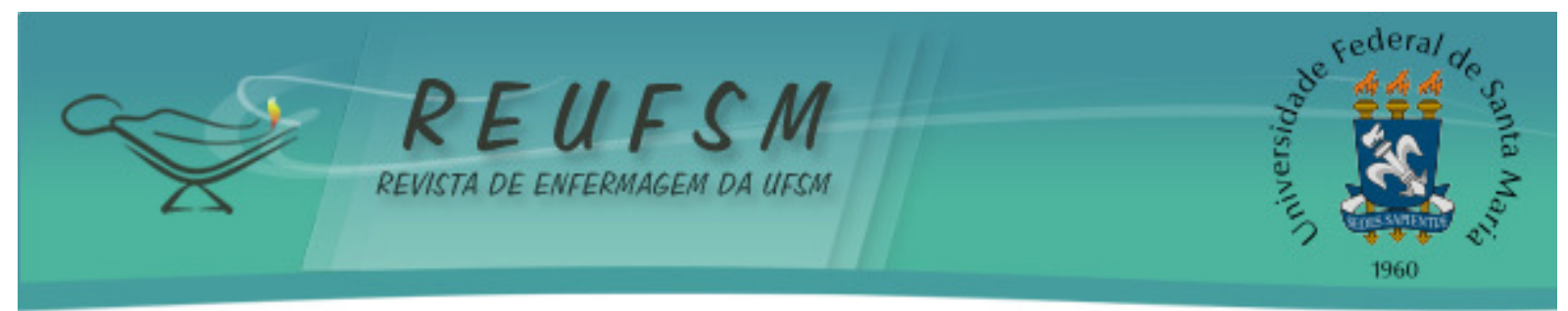

Encontrar o reconhecimento do trabalho dos profissionais foi algo motivador durante a realização do estudo. Além de caracterizar a equipe envolvida no cuidado, eles a avaliaram positivamente, 0 que pode ser compreendido como incentivo para os profissionais envolvidos e pelos estudantes, por se tratar de uma instituição de ensino.

Outro aspecto que merece destaque é o fato do SUS ser considerado um dos maiores planos de assistência médica do mundo, seja pelo número de pacientes cobertos (a rigor, todo cidadão brasileiro), seja pela complexidade de sua gestão. ${ }^{9}$ As críticas relacionadas ao seu atendimento aparecem com maior facilidade na mídia, por isso quando fatores positivos surgem devem ser enfatizados não somente como um retorno para o serviço, mas também como forma de valorização profissional para todos os envolvidos.

Em contraponto, a fala a seguir mostra a preocupação do paciente que presenciou uma situação de conflito na equipe de saúde:

A única coisa que eu fiquei achando estranho foi que houve um desentendimento no atendimento de uma clínica para outra. (D7US4)

Foi isso que eu achei estranho, porque eles estavam decidindo quem ia tomar conta de mim. (D7US6)

Tal relato desperta uma preocupação e cuidado que a equipe de saúde deve ter. Os pacientes em geral, quando hospitalizados, tendem a perder seus referenciais de segurança e a depositar, muitas vezes, na equipe de saúde o destino de suas vidas. Em pacientes cirúrgicos idosos esta confiança na equipe de saúde também é observada, sendo que eles sabem que se encontram em uma fase da vida com maiores riscos. Assim, dentro do ambiente hospitalar sentem-se inseguros, lidam com várias dificuldades e colocam sua confiança nas pessoas que estão cuidando dele. Nessas condições, coisas simples e por vezes banais para a equipe de saúde podem representar grande gravidade para o paciente cirúrgico idoso. Desta forma, consolida-se a importância da equipe de saúde valorizar a forma de interagir e comunicar-se com os pacientes. A equipe deve sempre considerar as peculiaridades e necessidades de segurança afetiva dos pacientes, estando atenta às conversas e procedimentos que executa, transmitindo segurança e conforto. ${ }^{10}$

A dimensão afetivo-expressiva faz parte da ação terapêutica do cuidado e pode ser explicitada pela relação de confiança, no trato com carinho, no ser gentil, no demonstrar compreensão, conversar, tocar, falar, escutar, olhar, dar força, interessar-se, aconselhar e outros. ${ }^{10}$

cuidado:

Outra lacuna no cuidado observada foi à falta de informações do próprio

Porque ninguém sabe que dia eu vou embora. (D2US12)

A falta de conhecimento em relação à data prevista para a alta caracteriza a fragilidade da equipe em expor a conduta ao paciente. A exteriorização verbal ou não verbal das atitudes afetivo-expressivas constitui os princípios fundamentais da enfermagem, merecendo atenção para tornarem-se uma prática no cotidiano de suas ações. Na área da saúde, é oportuno salientar que todo profissional necessita ter como base de seu trabalho as relações humanas, sejam elas com o cliente, com sua família ou com a equipe multidisciplinar. ${ }^{10}$

A situação de desconhecimento exposta pelo paciente cirúrgico idoso mostrou que é necessário orientar com clareza os aspectos relacionados à sua evolução após a cirurgia. 


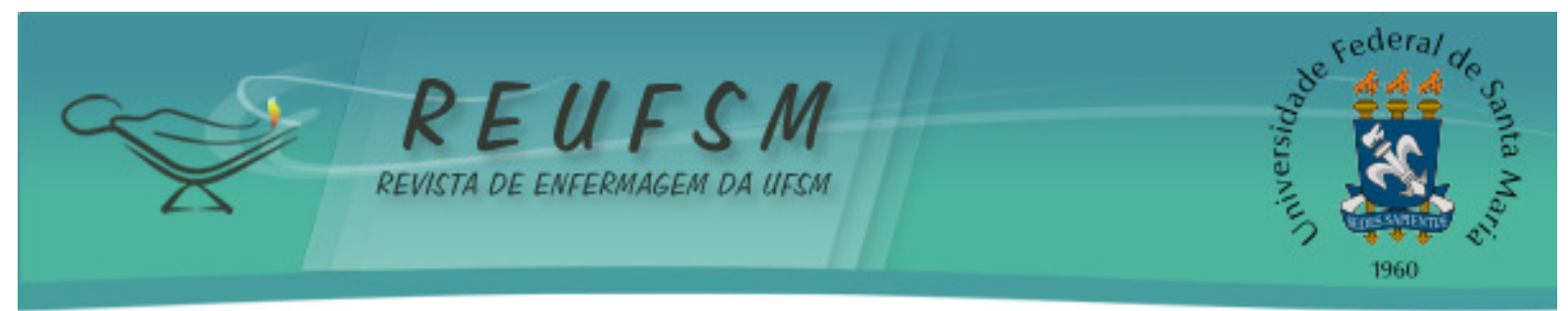

Estas informações precisam ser retomadas e validadas junto a ele, certificando-se de sua compreensão. Quando estas orientações não são feitas de forma adequada ele sente-se perdido. Para fortalecer as relações humanas entre profissionais e pacientes, buscando a humanização da assistência, é necessário que se invista nas tecnologias das relações. É preciso buscar espaços de discussão e reflexão sobre estas práticas, pois a assistência não necessita somente de equipamentos e tecnologias duras. O tratamento é mais eficaz quando a pessoa é acolhida, ouvida e sente-se respeitada pelos profissionais de saúde. ${ }^{11}$

A ausência de familiares também foi uma situação que emergiu, conforme ilustra o relato a seguir:

O povo pergunta para mim o "senhor é sozinho?" Eu falo não, eu tenho família. O senhor mora sozinho? Eu falo não, eu moro com a minha mulher e uma netinha que eu crio e um rapaz meu filho. (D2US10)

A presença de um familiar durante a internação é uma importante ligação com o meio externo, permitindo que o paciente idoso não se sinta restrito àquele lugar, uma vez que o familiar conhece suas particularidades e faz parte de sua vida, de sua rotina, de seu meio exterior ao hospital. ${ }^{12}$

A solidão hospitalar é, muitas vezes, vivenciada por pacientes idosos por não possuírem alguém próximo que possa acompanhá-los durante a internação, significando um desamparo emocional muito grande, deixando-o fragilizado. ${ }^{12}$

Da mesma forma, a dependência, que pode ser ocasionada em determinadas situações devido ao procedimento cirúrgico, gera a necessidade de cuidados especiais e de auxílio para a realização das atividades de vida diária, algo nem sempre possível de ser oferecido pelas famílias, podendo ocasionar situações em que o idoso não possua a atenção necessária. ${ }^{12}$

$\mathrm{Na}$ atual Política Nacional de Humanização da Saúde, assim como o Estatuto do idoso, em seu Art.16, a presença do acompanhante é assegurada, mas esta permissão fica na dependência de acordos e liberações institucionais que, na maioria das vezes, é decidida pelo enfermeiro das unidades de internação, demonstrando a responsabilidade do profissional frente a uma ação diferenciadora do tratamento. ${ }^{13}$

Essa tomada de decisão por vezes direcionada pelo enfermeiro enfatiza a importância desse profissional na humanização do cuidado, colaborando com situações em que a família ou amigos representados pelos acompanhantes façam parte do processo de recuperação do paciente.

0 acompanhamento de pacientes idosos também é referido em estudo onde a hospitalização é vista pelos filhos ou entes queridos como uma oportunidade de aproximação ou retribuição de algum cuidado recebido antes pela pessoa, fazendo com que a troca de cuidados fortaleça o laço afetivo. ${ }^{12}$

A espiritualidade demonstrada pelos pacientes evidenciou ser de grande impacto na sua recuperação.

Fé em Deus disse que amanhã eu vou embora. (D5US2)

É um pessoal tudo abençoado por Deus. (D6US11)

Os hospitais que possuem serviço de capelaria servem como um apoio para os pacientes colocarem em prática suas crenças religiosas, e os profissionais de enfermagem devem informá-los quanto à disponibilidade do serviço, deixando-os à vontade para 


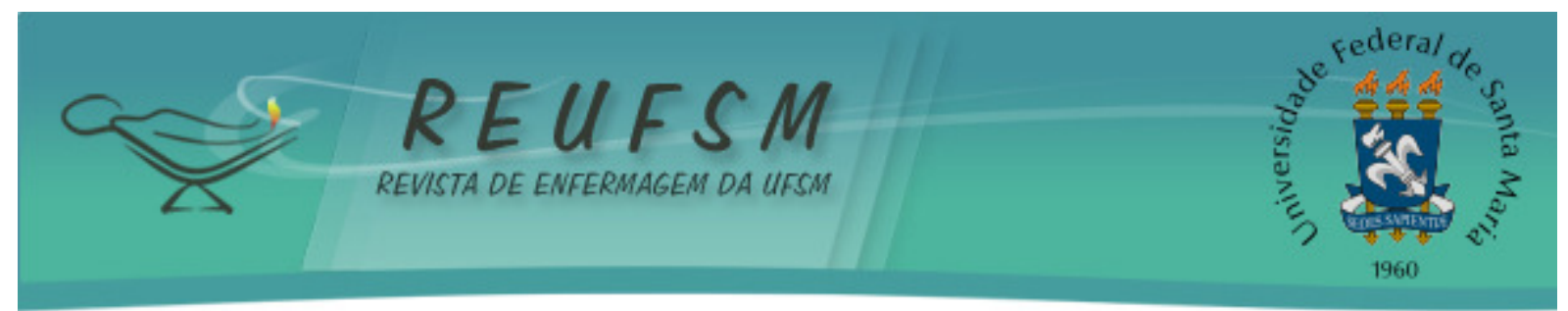

escolher se querem ou não o atendimento. Em experiência realizada em determinada enfermaria de geriatria, foi demonstrado que os pacientes vêem de forma positiva o atendimento religioso e sentem-se melhor após tal assistência. ${ }^{14}$

Com ética e respeito pelos valores religiosos e espirituais dos pacientes, é possível encontrar na religião e espiritualidade ferramentas úteis que podem auxiliar no atendimento a idosos internados. Estudo comenta que quando os pacientes utilizam a mente, cientes e crentes de sua força poderosa em transformar situações vivenciadas, invocada e aliada à fé religiosa, com o intuito de recuperar-se de um agravo, sentem-se mais felizes e com mais disposição para o enfrentamento das dificuldades, podendo, desta forma, provocar alterações em seu quadro. ${ }^{15}$

Os comportamentos religiosos são bastante frequentes na idade avançada. A espiritualidade e a força que alguns idosos encontram ao expressar a sua fé religiosa, explicam o porquê deles não se deprimirem e serem capazes de manter a esperança, enfrentando eficazmente doenças, como por exemplo, o câncer. ${ }^{15}$

\section{0 idoso e o autocuidado}

Nessa categoria foi revelada a visão de autocuidado pelo idoso. Alguns dos entrevistados fizeram referência em relação ao descuido com sua própria saúde e com seu autocuidado, como a seguir:

A gente cuida dos outros, mas não se lembra da gente. (D7US15)

O desconforto com o peso, influenciando a realização do autocuidado, foi citado na seguinte fala:

Porque eu não era para estar pesando o tanto que eu peso, estou pesando $85 \mathrm{~kg}$ queria ter $70 \mathrm{~kg}$ até poderia ser porque eu tenho 1,68 de altura então perto de $70 \mathrm{~kg}$ seria o ideal! (D4US13)

Os profissionais de saúde devem ter compromisso em ajudar os idosos no seu autocuidado. Em especial a equipe de enfermagem pode apoiá-los na realização de seu autocuidado, considerando as possibilidades e conhecimentos adquiridos no período de internação dos pacientes. É preciso que toda a equipe esteja imbuída deste propósito, expressando respeito pela capacidade individual de cada um, de acordo com as limitações e recursos disponíveis. ${ }^{16}$

O esforço demonstrado a cada dia no período de hospitalização foi visto pelos entrevistados como uma forma de autocuidado e superação. Para eles, cada mudança que conseguiam realizar sentiam-se mais próximos do momento de receber alta e esta condição significava autocuidado.

Eu me cuido, tipo assim, a direita (perna) que está doendo eu apoio mais e a esquerda (perna) eu estico e a direita eu não estico bem ela, mas eu mando colocar cobertas debaixo do calcanhar então eu me sinto bem. (D5US11)

Nessa fala é referido o autocuidado com a perna em que houve o procedimento cirúrgico, e a importância do posicionamento do membro para maior conforto da paciente.

0 autocuidado realizado pela paciente proporcionou uma sensação de bem-estar, demonstrando que é possível adaptar o ambiente para o alcance do conforto mesmo em 


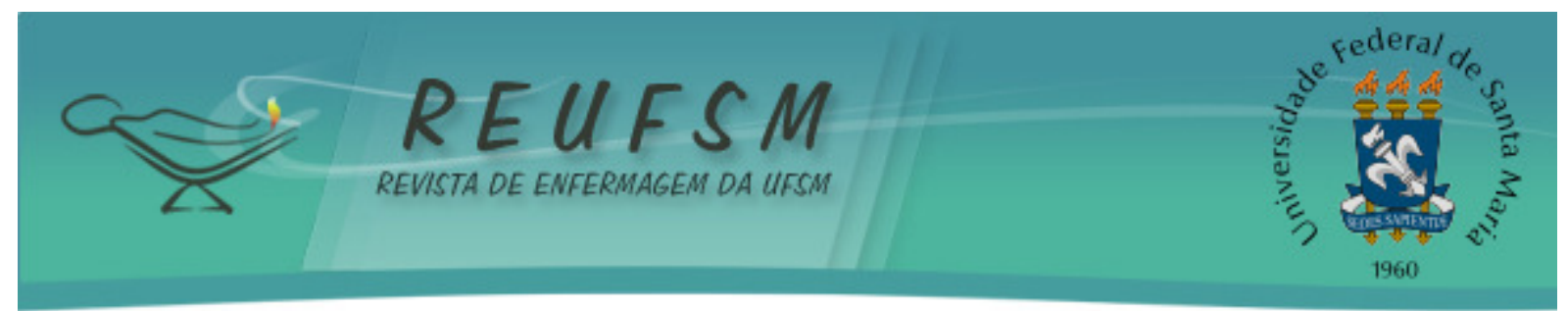

áreas hospitalares. Afirma-se que o ambiente hospitalar possui particularidades que o distanciam da realidade vivenciada pelos pacientes em suas casas, como pessoas desconhecidas no local, falta de objetos pessoais ou ausência de ações que o paciente considera necessário para se cuidar. ${ }^{17}$

Com isso, compete a equipe de saúde o esforço em proporcionar a ambiência necessária e propícia para que os pacientes desenvolvam o autocuidado. Um espaço onde possam buscar o conforto e a sociabilidade, mesmo distantes de seus lares e de seus familiares, abrindo possibilidades de autocuidado dentro dos ambientes hospitalares.

Em relação a outros aspectos, o cuidar da vida foi demonstrado como uma forma de autocuidado, de dar importância aos atos realizados, buscando em cada um deles uma especificação, uma melhora, ou até mesmo uma atividade. Reforçou-se a idéia de que o cuidar se inicia de duas formas: como um modo de sobreviver e como uma expansão de interesse e carinho. ${ }^{17}$

Eu me cuido assim: você está falando sobre a vida da gente? Eu me cuido assim quer ver: cuidar da minha família, como diz a história cuida de mim não me envolvo com a vida de ninguém, trato todo mundo bem, então vivo desse jeito, desse jeito, é meu jeito de viver. (D2US14)

Essa fala nos remete a reflexão que entre os idosos, temos o autocuidado como forma de valorização, de amor, pois cada um deles necessita sentir-se bem para que realize o seu cuidado, e também, devido à ausência de amigos que já faleceram ou da família distante, auto cuidar-se significa estar vivo.

\section{Significado de cuidar para o idoso}

Essa categoria busca revelar o significado de cuidar para o idoso.

Como significado de cuidado, os entrevistados citaram aspectos relacionais, afetivos e emocionais. Houve diferenciações entre homens e mulheres; a mulher considerou o significado mais voltado ao emocional e o homem mais à forma como direciona sua vida.

Cuidado acho que é pensar na vida, ter cuidado de não errar as coisas, fazer coisas erradas, não entrar no sacrifício depois se arrepender é tarde. (D2US15)

Cuidado é ter carinho né? É carinho, amor, paciência, perseverança é tudo isso. (D5US12)

Foi perceptível às pesquisadoras que o momento vivenciado pelos pacientes proporcionou maior reflexão sobre essa questão, influenciando na forma de olhar para o cuidado. Havia entrevistados satisfeitos com a cirurgia no período pós-operatório, outros sabiam que era apenas uma parte de uma etapa a ser vencida entre muitas outras que ainda estavam por vir.

A reflexão sobre o significado do cuidado remete a outros significados, como o próprio envelhecimento e suas mudanças, permitindo aos profissionais de saúde, criar razões que dêem significado a vida dos idosos. ${ }^{16}$ 


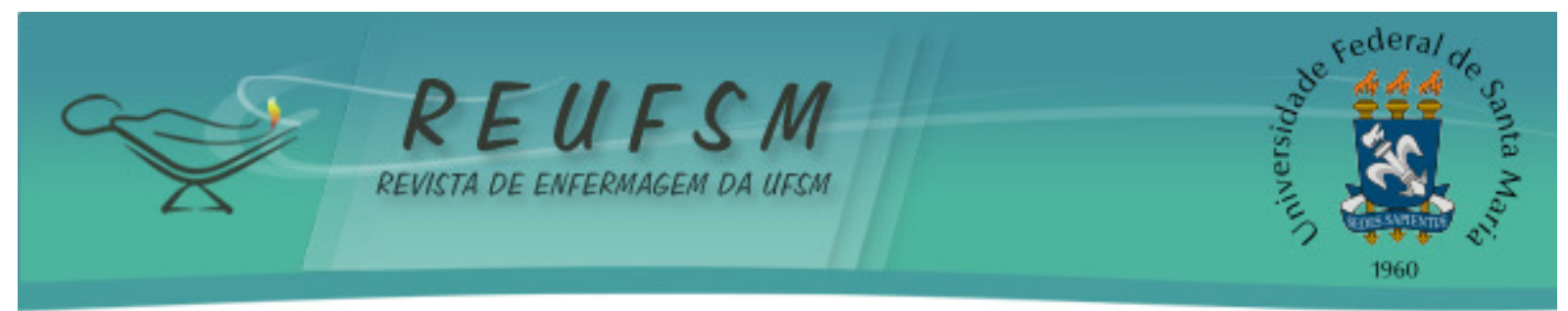

Diferente de uma proposta assistencialista, predominante nos modelos tradicionais, o cuidado representa a dinamicidade das múltiplas interações entre seres humanos, atingível na sua forma de Ser em sistemas abertos e ambientes mais saudáveis. A enfermagem deve utilizar o cuidado e seu significado como mola propulsora do atendimento, fazendo da humanização sua maior aliada. ${ }^{18}$

$\mathrm{Na}$ seguinte fala o paciente demonstra a importância do relacionamento humano na demonstração do cuidado:

Cuidado são as pessoas boas que cuidam bem da gente, que socorre a gente na hora que precisa que a gente pede ta ali para atender, não se afasta da gente quando a gente está sentindo mal. (D6US13)

0 momento da entrevista em que os significados de cuidado foram abordados permitiu perceber uma (re)construção na definição de alguns conceitos para os pacientes cirúrgicos idosos. Observaram-se pacientes esperançosos, determinados e com crença no melhor das pessoas e profissionais envolvidos. A experiência compartilhada pelos idosos na sua percepção de cuidado demonstra sua capacidade de sonhar, buscar algo inovador diante de uma cirurgia que, muitas vezes, é apresentada como única esperança de dias melhores.

Assim, ressaltou-se a importância dos significados de cuidado expressos pelos pacientes idosos participantes desta pesquisa. Enfatizou-se que qualquer que seja o hospital, independente da cirurgia, o idoso valoriza e considera imprescindível uma fala na hora certa, uma mão presente em momentos inesperados, uma atitude de amparo neste difícil momento de sua vida. É preciso desenvolver interesse profissional no contexto vivenciado pelo idoso, buscando suas particularidades que os tornam especiais de alguma forma, demonstrando apoio e carinho da equipe de saúde nos momentos necessários. ${ }^{18}$

\section{CONCLUSÃO}

O significado de cuidado para os idosos demonstrou singularidades de cada caso, sendo influenciado de acordo com o gênero e as experiências ao longo da vida. 0 contexto hospitalar influenciou diretamente a sensibilidade e a percepção de como estava sendo cuidado, referenciando de forma geral, como bem atendido pela instituição em estudo.

Concluiu-se que o cuidado representado em diferentes formas dentro do contexto da hospitalização pode influenciar no tratamento. No entanto, a presença da atenção, carinho e respeito por parte da equipe de saúde mostraram-se mais necessários em alguns casos do que a própria orientação sobre a cirurgia. 0 idoso, em todo o período perioperatório, expressou sentimentos de insegurança e ansiedade relacionados à questão do amparo psicológico e familiar mais fortemente do que em relação à compreensão do seu caso clínico.

Defendeu-se a necessidade de reflexão da equipe de saúde sobre resultados como os encontrados neste estudo. Deseja-se contribuir com esta temática reforçando a importância de atitudes de cuidado ao idoso hospitalizado, principalmente quando submetidos à procedimentos cirúrgicos, visando contribuir para o aperfeiçoamento e qualidade da assistência oferecida e fortalecer a humanização dos serviços de saúde.

\section{REFERÊNCIAS}

1. Quispe Mendonza IY, Peniche ACG. Conhecendo o perfil do idoso cirúrgico. Saúde Coletiva. 2009;6(30):104-8. 


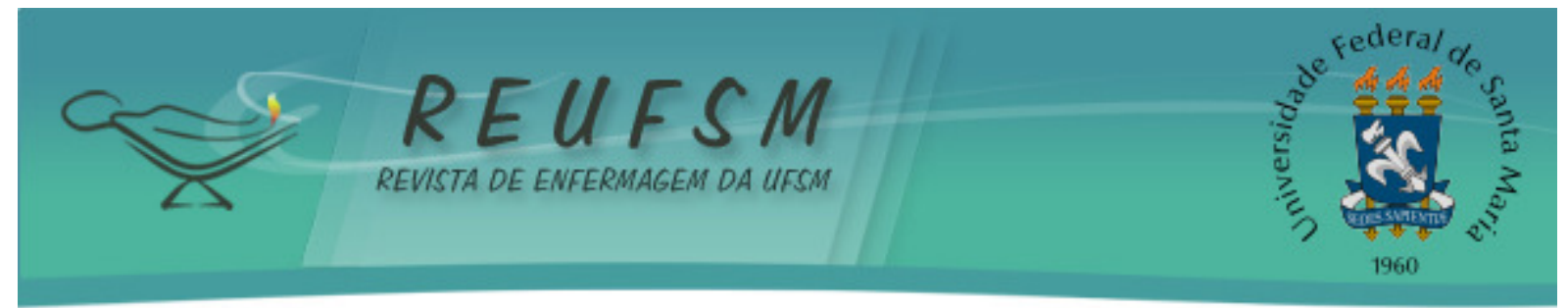

2. Hayashi JM, Garanhani ML. O cuidado perioperatório ao paciente ortopédico sob o olhar da equipe de enfermagem. REME Rev Min Enferm. 2012;16(2):208-16.

3. Souza LM, Wegner W, Gorini MIPC. Educação em saúde: uma estratégia de cuidado ao cuidador leigo. Rev Latinoam Enferm [Internet]. 2007 mar-abr [acesso em 2011 maio 2];15(2):337-43. Disponível em: http://www.scielo.br/pdf/rlae/v15n2/pt_v15n2a22.pdf.

4. Felix LG, Soares MJGO, Nóbrega MML. Protocolo de assistência de enfermagem ao paciente em pré e pós-operatório de cirurgia bariátrica. Rev Bras Enferm [Internet]. 2012 jan-fev [acesso em 2012 nov 20];65(1);83-91. Disponível em: http://www.scielo.br/pdf/reben/v65n1/12.pdf.

5. Semeniuk AP, Durman S, Matos FGOA. Saúde mental da equipe de enfermagem de centro cirúrgico frente à morte. Rev SOBECC. 2012;17(4):48-56.

6. Ribeiro RM, Tavano LA, Neme CMB. Intervenções psicológicas nos períodos pré e pósoperatório com pacientes submetidos a cirurgia de enxerto ósseo. Estud Psicol (Campinas) [Internet]. 2002 set-dez [acesso em 2011 jun 30];19(3):67-76. Disponível em: http://www.scielo.br/pdf/estpsi/v19n3/a07v19n3.pdf.

7. Martins J, Bicudo MAV. Pesquisa qualitativa em psicologia: fundamentos e recursos básicos. São Paulo: Centauro; 2005.

8. Razera APR, Braga EM. A importância da comunicação durante o período de recuperação pós-operatória. Rev Esc Enferm USP [Internet]. 2011 jun [acesso em 2013 jan 23];45(3):632-7.Disponível em: http://www.scielo.br/pdf/reeusp/v45n3/v45n3a12.pdf.

9. Freire RP, Pitassi C, Gonçalves AA, Schout D. Gestão de equipamentos médicos: o papel das práticas de qualidade em um hospital de excelência brasileiro. RAHIS Revista de Administração Hospitalar e Inovação em Saúde [Internet]. 2012 jan-jun [acesso em 2013 jan 20];8(8):30-43. Disponível em: http://web.face.ufmg.br/face/revista/index.php/rahis/article/view/1662.

10. Prochet TC, Silva MJP, Ferreira DM, Evangelista VC. Afetividade no processo de cuidar do idoso na compreensão da enfermeira. Rev Esc Enferm USP. 2012;46(1):96-102.

11. Fontana RT. Humanização no processo de trabalho em enfermagem: uma reflexão. Rev RENE [Internet]. 2010 jan-mar [acesso em 20 jan 2013];11(1):200-7. Disponível em: http: //www.revistarene.ufc.br/vol11n1_pdf/a21v11n1.pdf.

12. Carboni RM, Reppeto MA. Uma reflexão sobre a assistência a saúde do idoso no Brasil. Rev Eletrônica Enferm [Internet]. 2007 [acesso em 2011 maio 2];9(1):251-60. Disponível em: http://www.revistas.ufg.br/index.php/fen/article/view/7152/5064.

13. Pinheiro ALU, Beuter M, Brondani CM, Roso CC, Flores RG. Humanização no cuidado hospitalar: percepções de familiares e acompanhantes. Rev Enferm UFSM [Internet]. 2011 maio/ago [acesso em 2013 fev 5];1(2):204-13. Disponível em: http://cascavel.ufsm.br/revistas/ojs-2.2.2/index.php/reufsm/article/view/2525/1633.

14. Duarte FM, Wanderley KS. Religião e espiritualidade de idosos internados em uma enfermaria geriátrica. Psic Teor Pesq. 2011;27(1):49-53.

15. Teixeira JJV, Lefevre F. Significado da intervenção médica e da fé religiosa para o paciente idoso com câncer. Ciênc Saúde Coletiva [Internet]. 2008 jul-ago [acesso em 2013 fev 2];13(4):1247-56. Disponível em: http://www.scielo.br/pdf/csc/v13n4/21.pdf. 


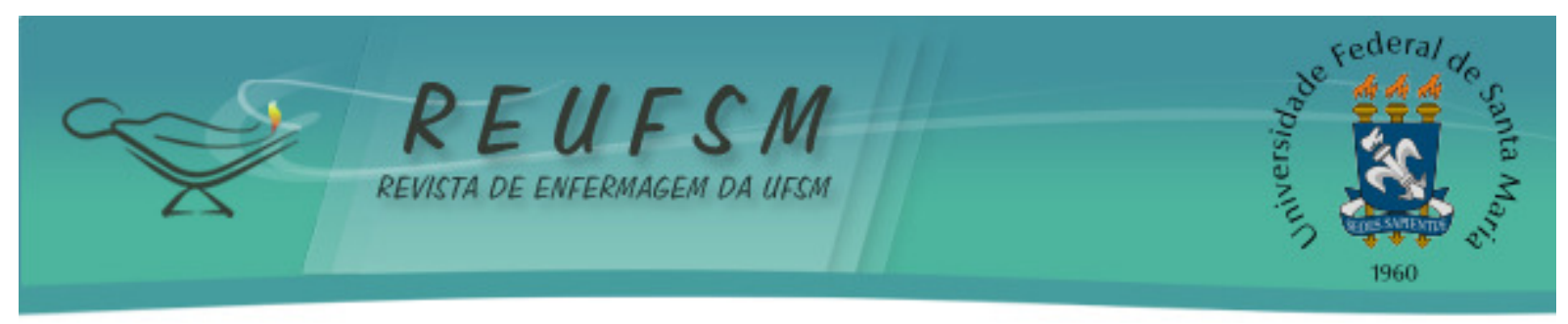

16. Freitas MC, Queiroz TA, Sousa JAV. O significado da velhice e da experiência de envelhecer para os idosos. Rev Esc Enferm USP [Internet]. 2010 jun [acesso em 2013 mar 5];44(2):407-12. Disponível em: http://www.scielo.br/pdf/reeusp/v44n2/24.pdf.

17. Waldow VR, Borges RF. O processo de cuidar sob a perspectiva da vulnerabilidade. Rev Latinoam Enferm [Internet]. 2008 jul-ago [acesso em 2013 mar 2];16(4):765-71. Disponível em: http://www.scielo.br/pdf/rlae/v16n4/pt_18.pdf.

18. Klock P, Rodrigues ACRL, Backes DS, Erdmann AL. O cuidado como produto de múltiplas interações humanas: importando-se com o outro. Cogitare Enferm [Internet]. 2007 out-dez [acesso em 2013 fev 2];12(4):452-9. Disponível em: http://ojs.c3sl.ufpr.br/ojs2/index.php/cogitare/article/view/10070/6922.

Data de recebimento: 02/08/2013

Data de aceite: $28 / 11 / 2013$

Contato com autor responsável: Simone Domingues Garcia

Endereço postal: Rua Carmela Dutra N ${ }^{\circ} 225$ ap 701B Jardim Morumbi

Londrina, PR CEP 86036-360

E-mail: sidomingues@yahoo.com.br 